\title{
Pengaruh Kesadaran Wajib Pajak, Pengetahuan Perpajakan, dan Sanksi Perpajakan Pada Kepatuhan Wajib Pajak UMKM
}

\author{
Efrie Surya Perdana ${ }^{1}$ \\ Fakultas Ekonomi dan Bisnis \\ Universitas Udayana, Indonesia \\ Email: efri_perdana@yahoo.com
}

\author{
A.A.N.B. Dwirandra2 \\ Fakultas Ekonomi dan Bisnis \\ Universitas Udayana, Indonesia
}

\begin{abstract}
ABSTRAK
Penelitianini bertujuan untuk mengetahui pengaruh kesadaran wajib pajak, pengetahuan perpajakan dan sanksi perpajakan pada kepatuhan wajib pajak UMKM yang terdaftar di KPP Pratama Tabanan. Penelitianini menggunakan data primer dan data sekunder. Data primer diperoleh dari jawaban terhadap serangkaian pernyataan dalam bentuk kuesioner kepada wajib pajak UMKM yang terdaftar di KPP Pratama Tabanan, sedangkan data sekunder berupa data jumlah wajib pajak UMKM yang terdaftar di KPP Pratama Tabanan. Sampel dalam penelitianini ditentukan dengan menggunakan metode stratified random sampling. Setelah memenuhi uji asumsi klasik, selanjutnya data dianalisis menggunakan teknik analisis regresi linier berganda. Hasil penelitian ini menunjukkan bahwa kesadaran wajib pajak, pengetahuan perpajakan, dan sanksi perpajakan berpengaruh positif dan signifikan pada kepatuhan wajib pajak UMKM yang terdaftar di KPP Pratama Tabanan.
\end{abstract}

Kata Kunci: Kesadaran Wajib Pajak; Pengetahuan Perpajakan; Sanksi Perpajakan; Kepatuhan Wajib Pajak UMKM.

\section{Effects of Taxpayer Awareness, Taxation Knowledge and Tax Sanctions on SMEs (UMKM) Taxpayer Compliance}

\section{ABSTRACT}

This study aims to determine the effect of awareness of taxpayers, tax knowledge and tax sanctions on UMKM taxpayer compliance registered at Tabanan Primary Tax Office. This research uses primary data and secondary data. Primary data were obtained from responses to a series of statements in the form of questionnaires to UMKM taxpayers registered at the Tabanan Primary Tax Office, while secondary datawas in the form of data on the number of UMKM taxpayers registered at the Tabanan Primary Tax Office. The sample in this study was determined using the stratified random sampling method. After fulfilling the classical assumption test, the data are then analyzed using multiple linear regression analysis techniques. The results of this study indicate that taxpayer awareness, tax knowledge, and tax sanctions have a positive and significant effect on tax compliance of UMKM registered at the Tabanan Primary Tax Office.

Keywords: $\quad$ Taxpayer Awareness; Taxation Knowledge; Tax sanctions; UMKM Taxpayer Compliance.

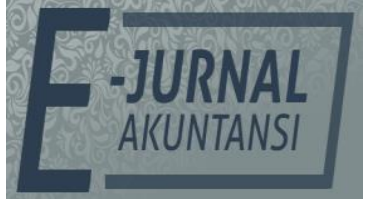

E-JA

e-Jurnal Akuntansi e-ISSN 2302-8556

Vol. 30 No. 6 Denpasar, Juni 2020

Hal.1458-1469

Artikel Masuk: 27 Januari 2020

Tanggal Diterima: 16 Maret 2020

This Article is Avalilable in: https://ojs.unud.ac.id/index.php/Akuntansi/index 


\section{PENDAHULUAN}

Pemerintah memenuhi kebutuhan dana dengan mengandalkan dua sumber pokok, yaitu sumber dana luar negeri dan sumber dana dalam negeri, sebagaimana yang tercantum dalam APBN (Afriyanti \& Sari, 2012). Sumber dana luar negeri misalnya hibah dan pinjaman luar negeri, sedangkan sumber dana dalam negeri seperti penjualan migas, non migas dan pajak. Penerimaan pajak merupakan seluruh pendapatan yang berasal atas pajak dalam negeri dan perdagangan internasional yang digunakan untuk belanja rutin maupun pembangunan negara dan daerahnya (Katini \& Suardana, 2017). Pajak memiliki fungsi regulerend dan fungsi budgetair. Fungsi budgetair adalah pajak yang berfungsi untuk memasukkan uang ke kas negara (Fuadi \& Mangoting, 2013). Sedangkan fungsi regulerend berarti pajak dijadikan sebagai alat pemerintah untuk mengatur tercapainya keseimbangan perekonomian.

Kepatuhan wajib pajak dalam melaksanakan kewajiban perpajakannya menjadi persoalan yang sangat penting di Indonesia karena wajib pajak yang tidak patuh dalam memenuhi kewajiban perpajakannya akan berdampak negatif terhadap negara yaitu berkurangnya penerimaan kas negara (Ariyanto et al., 2020). (Devos \& Zackrisson, 2015) menyatakan bahwa kepatuhan dalam wajib pajak dapat dikatakan sebagai kepatuhan dalam persyaratan pelaporan pajak dimana wajib pajak mengajukan dan melaporkan kewajiban sesuai peraturan yang berlaku. Kepatuhan wajib pajak dipengaruhi oleh dua faktor yaitu internal dan eksternal. Faktor internal merupakan faktor yang berasal dari dalam diri wajib pajak sendiri dan berhubungan dengan karakteristik individu yang menjadi pemicu dalam menjalankan kewajiban perpajakannya. Faktor eksternal merupakan faktor yang berasal dari luar diri wajib pajak seperti situasi dan lingkungan di sekitar wajib pajak (Mangoting \& Sadjiarto, 2013). Target dan Realisasi Penerimaan Negara dari sektor pajak tahun 2015-2018 dapat dilihat pada Tabel 1. berikut:

Tabel 1. Target dan Realisasi Penerimaan Negara Tahun 2015 - 2018 (Triliun Rupiah)

\begin{tabular}{cccc}
\hline Tahun & $\begin{array}{c}\text { Realisasi Penerimaan } \\
\text { Pajak }\end{array}$ & $\begin{array}{c}\text { Target Penerimaan } \\
\text { Pajak }\end{array}$ & $\begin{array}{c}\text { Persentase Realisasi } \\
\text { Penerimaan Pajak } \\
\text { (persen) }\end{array}$ \\
\hline 2015 & $1.060,83$ & $1.294,26$ & 81,96 \\
2016 & $1.105,81$ & $1.355,20$ & 81,60 \\
2017 & $1.151,03$ & $1.283,57$ & 89,67 \\
2018 & $1.315,51$ & $1.424,51$ & 92,24 \\
\hline
\end{tabular}

Sumber: Menu Kinerja Penerimaan Portal Direktorat Jendral Pajak, 2019

Berdasarkan Tabel 1 dapat diketahui bahwa penerimaan pajak dari tahun 2015 sampai 2018 selalu mengalami peningkatan dan peningkatan tersebut belum mencapai target yang telah ditetapkan oleh pemerintah. Persentase realisasi penerimaan negara dari sektor pajak meliputi semua jenis pajak, pada tahun 2015 adalah sebesar 81,96 persen, tahun 2016 persentase mengalami penurunan menjadi 81,60 persen, tahun 2017 meningkat menjadi 89,67 persen dan tahun 2019 sebesar 92,24 persen. Namun permasalahan utama pepajakan di Indonesia adalah tingkat kepatuhan wajib pajak yang masih perlu untuk ditingkatkan. 
Undang-Undang Republik Indonesia Nomor 20 Tahun 2008 Tentang Usaha Mikro, Kecil, dan Menengah pasal 1 "usaha mikro kecil menengah adalah usaha produktif yang berdiri sendiri yang dilakukan oleh perorangan atau badan usaha yang bukan merupakan anak perusahaan atau cabang perusahaan yang dimiliki, dikuasai, atau menjadi bagian baik langsung maupun tidak langsung". Usaha Mikro Kecil Menengah (UMKM) merupakan bagian dari sektor dunia usaha nasional yang mempunyai kedudukan, potensi dan peran yang strategis dalam mewujudkan tujuan pembangunan nasional berdasarkan demokrasi ekonomi yang berkeadilan. Tingkat kepatuhan wajib pajak UMKM di KPP Pratama Tabanan dalam Pelaporan SPT dapat dilihat pada Tabel 2. berikut.

Tabel 2. Tingkat Kepatuhan Wajib Pajak UMKM dalam Pelaporan SPT di KPP Pratama Tabanan Tahun 2015-2018

\begin{tabular}{ccccc}
\hline Tahun & $\begin{array}{c}\text { WP UMKM } \\
\text { Terdaftar }\end{array}$ & $\begin{array}{c}\text { WP UMKM } \\
\text { Wajib lapor SPT }\end{array}$ & $\begin{array}{c}\text { WP UMKM yang } \\
\text { menyampaikan SPT }\end{array}$ & $\begin{array}{c}\text { Kepatuhan } \\
\text { (persen) }\end{array}$ \\
\hline 2015 & 25.461 & 12.629 & 3.059 & 24,22 \\
2016 & 27.120 & 13.031 & 3.901 & 29,94 \\
2017 & 29.998 & 12.975 & 4.554 & 35,09 \\
2018 & 32.751 & 13.952 & 7.209 & 51,67 \\
\hline
\end{tabular}

Sumber: KPP Pratama Tabanan, 2019

Tabel 2 dapat dilihat bahwa tingkat kepatuhan wajib pajak UMKM di Tabanan dalam hal pelaporan SPT mengalami peningkatan dari tahun 2015-2018. Pada tahun 2016 tingkat kepatuhan wajib pajak UMKM mengalami peningkatan dari tahun 2015 yang awalnya 24,22 persen menjadi 29,92 persen. Tahun 2017 kembali mengalami peningkatan menjadi 35,09 persen dan pada tahun 2018, tingkat kepatuhan wajib pajak UMKM mengalami peningkatan yang signifikan menjadi 51,61 persen. Tingkat kepatuhan wajib pajak UMKM dalam hal pelaporan SPT di Tabanan masih harus ditingkatkan kembali karena jumlah wajib pajak UMKM yang melaporkan SPT berjumlah 7.209 wajib pajak dari 13.952 wajib pajak yang wajib melaporkan SPTnya, dan persentase tingkat kepatuhan wajib pajak dalam melaporkan SPT masih dibawah 100 persen/ sebesar 51,61 persen.

Teori kepatuhan (compliance theory) merupakan teori yang menjelaskan suatu kondisi dimana seseorang taat terhadap perintah atau peraturan yang diberikan (Handke \& Barthauer, 2019). Kepatuhan wajib pajak dapat dipengaruhi oleh beberapa faktor, seperti sanksi perpajakan, kesadaran wajib pajak, dan pengetahuan perpajakan. Hasil penelitian sebelumnya yang dilakukan oleh (Budhiartama \& Jati, 2016), (Susilawati \& Budiartha, 2013), (Sari \& Wirakusuma, 2018), (Cahyani \& Noviari, 2019), (Muliari \& Setiawan, 2010) dan (Adnyana \& Jati, 2018) menunjukan bahwa sanksi perpajakan, pengetahuan perpajakan dan kesadaran wajib pajak berpengaruh positif dan signifikan terhadap kepatuhan wajib pajak. Sedangkan penelitian yang dilakukan oleh (Karsimiati, 2009), (Sentanu \& Setiawan, 2016), (Hardiningsih \& Yulianawati, 2011), Markhumah et al. (2019) dan Nugroho et al. (2016) menunjukan bahwa sanksi perpajakan, kesadaran wajib pajak dan pegetahuan perpajakan tidak berpengaruh terhadap kepatuhan wajib pajak. Penelitian ini menggunakan variabel kesadaran wajib pajak, pengetahuan perpajakan dan sanksi perpajakan sebagai faktor yang mempengaruhi kepatuhan wajib pajak, hal ini disebabkan 
karena adanya perbedaan antara hasil penelitian- penelitian sebelumnya, sehingga peneliti tertarik untuk memilih variabel-variabel tersebut untuk diteliti kembali.

Kesadaran wajib pajak merupakan faktor yang dapat mempengaruhi wajib pajak untuk memenuhi kewajiban perpajakannya (Ariyanto et al., 2020). Andreas \& Savitri, (2015) kesadaran wajib pajak merupakan suatu kondisi dimana wajib pajak mengetahui, memahami, menghitung, membayar dan melaksanakan kewajiban pajak dengan sukarela. Semakin tinggi kesadaran wajib pajak maka pemahaman dan pelaksanaan kewajiban perpajakan semakin baik sehingga dapat meningkatkan kepatuhan (Muliari \& Setiawan, 2010). Bila seseorang hanya mengetahui dan tidak memahami serta tidak melaksanakan ketentuan (hukum pajak) berarti kesadaran hukum orang tersebut masih rendah (Suriambawa \& Setiawan, 2018).

Pemahaman akan arti dan manfaat pajak dapat meningkatkan kesadaran dari wajib pajak (Ariyanto et al., 2020). Pengetahuan pajak yang cukup dapat mempengaruhi tingkat kepatuhan seorang wajib pajak (Manual \& Zhi Xin, 2016). Tanpa adanya pengetahuan tentang pajak dan manfaatnya tidak mungkin orang secara ikhlas membayar pajak (Ariyanto et al., 2020). Kekhawatiran masyarakat dalam membayar pajak disebabkan oleh maraknya kasus yang sering terjadi khususnya dibidang perpajakan. Pengetahuan perpajakan yang dimiliki wajib pajak merupakan hal paling mendasar yang harus dimiliki wajib pajak karena tanpa adanya pengetahuan tentang pajak, sangat sulit bagi wajib pajak dalam menjalankan kewajiban perpajakannya (Ariyanto et al., 2020). Pemerintah telah melakukan upaya untuk menambah pengetahuan wajib pajak melalui penyuluhan dan iklan di media masa dengan tujuan agar para wajib pajak lebih mudah mengerti dan cepat mendapat informasi perpajakan sehingga proses perpajakan bisa berjalan dengan lancar.

Faktor lain yang bisa mempengaruhi kepatuhan wajib pajak adalah sanksi perpajakan. Kepatuhan wajib pajak dapat diwujudkan dengan penegakan sanksi (Budhiarsana et al. 2016). Sanksi perpajakan akan memberikan jaminan bahwa peraturan perpajakan akan dipatuhi. Wajib pajak akan patuh (karena tekanan) terhadap kewajiban perpajaknya apabila sanksi perpajakan akan lebih memberatkan atau merugikan. Konsekuensi hukum yang diberikan akibat melanggar pajak seperti sanksi administrasi dan sanksi pidana.

Teori Perilaku Terencana (Theory of Planned Behavior) merupakan niat seseorang dalam berprilaku (Ajzen, 2005). Niat seseoorang ditentukan oleh behavior belief, normatif belief, dan control belief (Sulistiyani, 2016) dan (Ghouri et al, 2016). Berdasarkan teori ini, kesadaran wajib pajak berkaitan dengan behavior belief yang menjelaskan bahwa sikap individu akan memengaruhi keinginan individu dalam bertindak dengan mengetahui hasil dari tindakan yang dilakukan individu tersebut. Dalam kaitannya dengan teori kepatuhan, kesadaran wajib pajak yang tinggi akan mempengaruhi tingkat kepatuhan dimana semakin sadar wajib pajak maka tingkat kepatuhan akan meningkat. Kesadaran adalah dimana setiap elemen manusia dalam memahami realitas dan bagaimana bereaksi atau merespon realita (Nurlis \& Islamiah Kamil, 2015). Kesadaran dan kepatuhan wajib pajak adalah suatu kondisi dimana wajib pajak 
mengetahui, memahami, dan melaksanakan kewajiban perpajakannya dengan benar dan sukarela (Intrada et al. 2019). (Nurkhin et al. 2018) dan (Muliari \& Setiawan, 2010) melakukan penelitian terhadap pengaruh kesadaran wajib pajak terhadap kepatuhan wajib pajak. Hasil penelitian ini terdapat pengaruh yang signifikan dan positif terhadap kepatuhan wajib pajak. Berdasarkan landasan teori dan penelitian tersebut, dapat dirumuskan hipotesis sebagai berikut:

$\mathrm{H}_{1}$ : Kesadaran wajib pajak berpengaruh positif pada kepatuhan wajib pajak UMKM.

Berdasarkan Teori Perilaku Terencana (Theory of Planned Behavior), pengetahuan perpajakan berkaitan dengan normatif belief yang merupakan harapan yang dipersepsikan satu orang atau lebih untuk menyetujui suatu perilaku dan memotivasi seseorang dalam mematuhi kewajibannya. Dalam kaitannya dengan teori kepatuhan, pengetahuan perpajakan yang memadai akan mempermudah wajib pajak dalam memenuhi kewajiban perpajakannya. Elemen penting dalam sistem pajak sukarela adalah pengetahuan perpajakan (Saad, 2013) dan (Ariyanto et al., 2020). Pengetahuan Pajak yaitu langkah pendewasaan pemikiran seorang wajib pajak melalui upaya pengajaran dan pelatihan (Hardiningsih \& Yulianawati, 2011). Menurut (Brainyyah, 2013) Pengetahuan perpajakan adalah segala informasi yang berkaitan dengan perpajakan yang digunakan untuk bertindak, membuat kesimpulan, dan untuk mengembangkan strategi tertentu yang mengarah untuk memenuhi hak pembayaran dan kewajiban pajak. (Susilawati \& Budiartha, 2013) melakukan penelitian terhadap pengaruh pengetahuan perpajakan menunjukkan pengaruh yang positif dan signifikan antara pengetahuan perpajakan terhadap kepatuhan wajib pajak. Berdasarkan landasan teori dan penelitian tersebut, dapat dirumuskan hipotesis sebagai berikut:

$\mathrm{H}_{2}$ : Pengetahuan perpajakan berpengaruh positif pada kepatuhan wajib pajak UMKM.

Berdasarkan Teori Perilaku Terencana (Theory of Planned Behavior), sanksi perpajakan berkaitan dengan control belief yang merupakan keyakinan seseorang tentang keberadaan suatu hal yang menghambat atau mendukung perilaku individu tersebut. Dalam kaitannya dengan teori kepatuhan, sanksi pepajakan akan mendorong seseorang dalam mematuhi aturan yang berlaku. Fischer et al. (1992) mengatakan bahwa sanksi perpajakan adalah faktor penting dalam menentukan kepatuhan wajib pajak. Semakin tinggi sanksi yang diberikan maka tingkat kepatuhan akan semakin tinggi (Lewis, 1992). Wajib pajak akan mematuhi kewajiban perpajakannya apabila sanksi yang diberikan lebih merugikan wajib pajak tersebut. (Cahyani \& Noviari, 2019) melakukan penelitian pengaruh Sanksi Perpajakan terhadap Kepatuhan Wajib Pajak menunjukkan bahwa Sanksi Perpajakan berpengaruh positif dan signifikan terhadap Kepatuhan Wajib Pajak. Berdasarkan teori dan penelitian tersebut, dapat dirumuskan hipotesis sebagai berikut:

$\mathrm{H}_{3}$ : Sanksi perpajakan berpengaruh positif pada kepatuhan wajib pajak UMKM. 


\section{METODE PENELITIAN}

Lokasi penelitian ini dilakukan pada wajib pajak UMKM yang terdaftar di Kantor Pelayanan Pajak Pratama Kabupaten Tabanan. Objek dari penelitian ini yaitu Pengaruh Kesadaran Wajib Pajak $\left(X_{1}\right)$, Pengetahuan Perpajakan $\left(X_{2}\right)$, dan Sanksi Perpajakan $\left(X_{3}\right)$ pada Kepatuhan Wajib Pajak UMKM (Y).

Populasi dalam penelitian ini adalah seluruh Wajib Pajak UMKM yang terdaftar di KPP Pratama Tabanan dengan jumlah 32.751 wajib pajak. Guna efisiensi waktu dan biaya, maka tidak semua wajib pajak tersebut menjadi objek dalam penelitian ini. Pengambilan sampel dalam penelitian ini dilakukan dengan menggunakan metode stratified random sampling dengan memperhatikan stara (tingkatan) didalam populasi. Berdasarkan perhitungan maka jumlah sampel yang diambil dalam penelitian ini adalah sebanyak 100 sampel wajib pajak UMKM yang terdaftar di KPP Pratama Tabanan.

Analisis regresi yang digunakan dalam penelitian ini yaitu analisis regresi linear berganda yang diuji dengan tingkat signifikansi $\alpha=0,05$. Persaman regresi yang dirumuskan berdasarkan hipotesis yang telah dibuat adalah sebagai berikut:

$$
\hat{\mathrm{Y}}=\alpha+\beta_{1} X_{1}+\beta_{2} X_{2}+\beta_{3} X_{3}+\varepsilon
$$

Keterangan

$$
\begin{array}{ll}
\hat{Y} & : \text { Kepatuhan Wajib Pajak } \\
\alpha & : \text { Konstanta } \\
\beta & : \text { Koefisien Regresi } \\
X_{1} & : \text { Kesadaran Wajib Pajak } \\
X_{2} & : \text { Pengetahuan Perpajakan } \\
X_{3} & : \text { Sanksi Perpajakan } \\
\varepsilon & : \text { Error }
\end{array}
$$

\section{HASIL DAN PEMBAHASAN}

Statistik deskriptif bertujuan untuk memberikan informasi mengenai karakteristik variabel-variabel penelitian Hasil uji statistik deskriptif dapat dilihat pada Tabel 3. sebagai berikut:

Tabel 3. Hasil Statistifk Deskriptif

\begin{tabular}{lccccc}
\hline \multicolumn{1}{c}{ Variabel } & N & Min & Max & Mean & Deviation \\
\hline KesadaranWajib Pajak & 100 & 3 & 5 & 4,12 & 0,485 \\
Pengetahuan Perpajakan & 100 & 2 & 5 & 4,04 & 0,526 \\
Sanksi Perpajakan & 100 & 3 & 5 & 4,15 & 0,405 \\
Kepatuhan Wajib Pajak & 100 & 3 & 5 & 4,16 & 0,390 \\
Valid N (listwise) & 100 & & & & \\
\hline
\end{tabular}

Sumber: Data Penelitian, 2019

Variabel kesadaran wajib pajak memiliki nilai minimum sebesar 3 dan nilai maksimum sebesar 5 . Nilai rata-rata untuk variabel kesadaran wajib pajak adalah 4,12 dengan penyimpangan sebesar 0,485. Variabel pengetahuan perpajakan memiliki nilai minimum sebesar 2 dan nilai maksimum sebesar 5 . Nilai rata-rata untuk variabel pengetahuan perpajakan adalah 4,04 dengan penyimpangan sebesar 0,526. Variabel sanksi perpajakan memiliki nilai minimum sebesar 3 dan nilai maksimum sebesar 5 . Nilai rata-rata untuk variabel sanksi perpajakan adalah 4,15 dengan penyimpangan sebesar 0,405. Variabel 
kepatuhan wajib pajak memiliki nilai minimum sebesar 3 dan nilai maksimum sebesar 5. Nilai rata-rata untuk variabel kepatuhan wajib pajak adalah 4,16 dengan penyimpangan sebesar 0,390.

Perhitungan Koefisien regresi linier berganda dilakukan dengan analisis regresi menggunakan software SPSS 24 dan diperoleh hasil yang ditunjukkan pada Tabel 4. berikut:

Tabel 4. Hasil Analisis Regresi Linier Berganda

\begin{tabular}{|c|c|c|c|c|}
\hline Variabel & Unstandarlized Beta & Std. Error & Sig. & $\begin{array}{c}\text { Hasil Uji } \\
\text { Hipotesis }\end{array}$ \\
\hline$\overline{\text { Constant }}$ & 8,468 & 1,975 & 0,000 & \\
\hline Kesadaran Wajib Paj & 0,214 & 0,104 & 0,043 & $\mathrm{H}_{1}$ diterima \\
\hline Pengetahuan Perpajakan & 0,306 & 0,056 & 0,000 & $\mathrm{H}_{2}$ diterima \\
\hline Sanksi Perpajakan & 0,260 & 0,123 & 0,037 & $\mathrm{H}_{3}$ diterima \\
\hline
\end{tabular}

Sig F $=0,000$

Adj R $\quad=0,480$

Sig adj $\mathrm{R} \quad=0,000$

Sumber: Data Penelitian, 2019

Berdasarkan hasil analisis regresi linier berganda seperti yang disajikan pada Tabel 4. maka dapat dibuat persamaan regresi sebagai berikut.

$$
\hat{\mathrm{Y}}=8,468+0,214 \mathrm{X}_{1}+0,306 \mathrm{X}_{2}+0,260 \mathrm{X}_{3}
$$

Nilai koefisien regresi masing-masing variabel bebas dengan tanda positif dengan nilai signifikansi uji t kurang dari $\alpha=0,05$. Hal ini menunjukkan bahwa semua variabel bebas memiliki pengaruh positif dan signifikan pada variabel terikat.

Uji kelayakan model (uji F) digunakan untuk mengetahui besar model memprediksi kepatuhan wajib pajak UMKM (Y) dengan menerangkan nilai kepatuhannya. Apabila nilai signifikansi uji $\mathrm{F}$ lebih kecil dari 0,05 maka hubungan antar variabel bebas adalah signifikan dan model regresi yang digunakan dianggap layak uji.

Berdasarkan Tabel 4. dapat dilihat bahwa signifikansi uji F sebesar 0,000 yang lebih kecil dari $\alpha=0,05$. Hal ini menunjukkan bahwa variabel kesadaran wajib pajak, pengetahuan perpajakan dan sanksi perpajakan berpengaruh secara serempak pada variabel kepatuhan wajib pajak. Koefisien determinasi digunakan untuk mengukur seberapa jauh kemampuan variabel independen dalam menjelaskan perubahan/vasiasi variabel dependen. Adapun hasil uji koefisien determinasi dalam penelitian ini dapat dilihat pada Tabel 4.

Berdasarkan Tabel 4. diperoleh nilai adj $R$ sebesar 0,480 yang mempunyai arti bahwa sebesar 48,0\% variabel kepatuhan wajib pajak dipengaruhi oleh variabel kesadaran wajib pajak, pengetahuan perpajakan, dan sanksi perpajakan, sedangkan sisanya sebesar 52,0\% dijelaskan oleh faktor lain yang tidak dimasukkan ke dalam model.

Uji t digunakan untuk menunjukkan pengaruh semua variabel independen secara parsial pada variabel dependen. Kriteria pengujian untuk menjelaskan interpretasi pengaruh antara masing-masing variabel yaitu apabila nilai signifikansi < 0,05 maka H0 ditolak dan H1 diterima. Sebaliknya, jika nilai signifikansi > 0,05 maka $\mathrm{H} 0$ diterima dan $\mathrm{H} 1$ ditolak. Hasil uji $\mathrm{t}$ dapat dilihat pada Tabel 4. 
Berdasarkan Tabel 4. hasil analisis pengaruh kesadaran wajib pajak pada kepatuhan wajib pajak diperoleh nilai signifikasi sebesar 0,043. Nilai Signifikansi $0,043<0,05$ mengindikasikan bahwa H1 diterima. Hasil ini mempunyai arti bahwa kesadaran wajib pajak berpengaruh positif dan signifikan pada kepatuhan wajib pajak.

Berdasarkan Tabel 4. hasil analisis pengaruh pengetahuan perpajakan pada kepatuhan wajib pajak diperoleh nilai signifikasi sebesar 0,000. Nilai Signifikansi $0,000<0,05$ mengindikasikan bahwa H2 diterima. Hasil ini mempunyai arti bahwa pengetahuan perpajakan berpengaruh positif dan signifikan pada kepatuhan wajib pajak.

Berdasarkan Tabel 4. hasil analisis pengaruh sanksi perpajakan pada kepatuhan wajib pajak diperoleh nilai signifikasi sebesar 0,037. Nilai Signifikansi $0,037<0,05$ mengindikasikan bahwa H3 diterima. Hasil ini mempunyai arti bahwa sanksi perpajakan berpengaruh positif dan signifikan pada kepatuhan wajib pajak.

Hipotesis pertama pada penelitian ini adalah kesadaran wajib pajak berpengaruh positif pada kepatuhan wajib pajak UMKM. Hasil pengujian yang dilakukan menggunakan regresi linier berganda sejalan dengan hipotesis yang telah dirumuskan yaitu kesadaran wajib pajak berpengaruh positif dan signifikan pada kepatuhan wajib pajak UMKM. Nilai regresi menunjukkan nilai koefisien positif yaitu sebesar 0,214 dengan nilai signifikansi 0,043 <0,05. Hasil dari pengujian ini berarti bahwa semakin sadar wajib pajak akan kewajiban perpajakannya maka tingkat kepatuhan wajib pajak akan semakin meningkat. Temuan ini mendukung theory of planned behavior dan teori kepatuhan, dimana ketika seseorang memiliki kesadaran yang tinggi akan kewajibannya sebagai wajib pajak maka orang tersebut akan taat dan patuh dalam melaksanakan kewajiban perpajaknya.

Hasil penelitian sebelumnya yang dilakukan oleh (Nurkhin et al. 2018) dan Muliari \& Setiawan (2010) menunjukkan bahwa kesadaran wajib pajak berpengaruh signifikan dan positif terhadap kepatuhan wajib pajak (Ariyanto et al., 2020). Penelitian ini tidak sesuai dengan penelitian yang dilakukan oleh Nugroho et al. (2016) yang menyatakan kesadaran wajib pajak tidak berpengaruh secara parsial terhadap kepatuhan wajib pajak. Seperti diketahui bahwa tingkat kepatuhan wajib pajak yang dijadikan sampel masih belum maksimal, oleh karena itu perlu adanya solusi untuk meningkatkan kepatuhan. Dalam kaitannya dengan kesadaran wajib pajak, berdasarkan uraian data statistik dapat diketahui bahwa persepsi kepercayaan masyarakat tentang pajak masih rendah, oleh karena itu perlu diadakannya sosialisasi dan transparansi pajak guna meningkatkan kesadaran wajib pajak.

Hipotesis kedua pada penelitian ini adalah pengetahuan perpajakan berpengaruh positif pada kepatuhan wajib pajak UMKM. Hasil pengujian yang dilakukan menggunakan regresi linier berganda sejalan dengan hipotesis yang dirumuskan yaitu pengetahuan perpajakan berpengaruh positif dan signifikan pada kepatuhan wajib pajak. Nilai regresi menunjukkan nilai koefisien positif sebesar 0,306 dengan nilai signifikansi $0,000<0,05$. Hasil dari pengujian ini berarti bahwa semakin memadai pengetahuan wajib pajak terkait perpajakan maka tingkat kepatuhan wajib pajak akan semakin meningkat. Temuan ini 
mendukung theory of planned behavior dan teori kepatuhan, dimana ketika seseorang diberikan pengetahuan yang cukup tentang perpajakan maka orang tersebut akan menjadi tau dan memiliki perilaku yang patuh (Handayani, 2018).

Hasil penelitian sebelumnya yang dilakukan oleh Susilawati \& Budiartha (2013) dan (Ariyanto et al., 2020)menunjukkan bahwa pengetahuan perpajakan berpengaruh positif dan signifikan terhadap kepatuhan wajib pajak. Penelitian ini tidak sesuai dengan penelitian yang dilakukan oleh Markhumah (2019) yang menyatakan pengetahuan perpajakan tidak berpengaruh terhadap kepatuhan wajib pajak. Seperti diketahui bahwa tingkat kepatuhan wajib pajak yang dijadikan sampel masih belum maksimal, oleh karena itu perlu adanya solusi untuk meningkatkan kepatuhan. Dalam kaitan dengan pengetahuan perpajakan berdasarkan uraian data statistik dapat diketahui bahwa persepsi masyarakat tentang tarif pajak yang diterapkan saat ini dianggap tidak sesuai, oleh karena itu perlu diadakan sosialisasi dan edukasi yang berkelanjutan untuk meningkatkan pengetahuan wajib pajak.

Hipotesis ketiga pada penelitian ini adalah sanksi perpajakan berpengruh positif pada kepatuhan wajib pajak UMKM. Hasil pengujian yang dilakukan menggunakan regresi linier berganda sejalan dengan hipotesis yang dirumuskan yaitu sanksi perpajakan berpengaruh positif dan singnifikan pada kepatuhan wajib pajak UMKM. Nilai regresi menunjukkan nilai koefisien positif sebesar 0,260 dengan nilai signifikansi $0,037<0,05$. Hasil dari pengujian ini berarti bahwa semakin tegas sanksi yang diberikan kepada wajib pajak yang melanggar pajak, maka tingkat kepatuhan wajib pajak akan semakin meningkat. Temuan ini mendukung theory of planned behavior dan teori kepatuhan (compliance theory), dimana ketika seseorang diberikan pemahaman tentang sanksi yang memberatkan bila dilanggar, maka orang tersebut akan menjadi takut untuk melanggar dan lebih cenderung akan patuh akan kewajiban perpajakannya.Hasil penelitian sebelumnya yang dilakukan oleh Cahyani \& Noviari, (2019) menunjukkan bahwa sanksi perpajakan berpengaruh positif dan signifikan terhadap kepatuhan wajib pajak. Penelitian ini tidak sesuai dengan penelitian yang dilakukan oleh Sentanu \& Setiawan (2016) dan Setiawan (2015) yang menyatakan sanksi perpajakan tidak berpengaruh pada kepatuhan wajib pajak. Seperti diketahui bahwa tingkat kepatuhan wajib pajak yang dijadikan sampel masih kurang maksimal, oleh karena itu perlu adanya solusi untuk meningkatkan kepatuhan. Dalam kaitan dengan sanksi perpajakan berdasarkan uraian data statistik dapat diketahui bahwa persepsi masyarakat tentang sanksi yang dikenakan bagi wajib pajak yang melanggar masih dianggap kurang tegas, oleh karena itu perlu diadakan sosialisasi dan pemeriksaan yang tegas kepada wajib pajak untuk memperbaiki tingkat kepatuhan wajib pajak.

\section{SIMPULAN}

Hasil yang ditunjukkan dari penelitian ini dan teori-teori yang digunakan dapat mendukung hasil penelitian dan memberikan pemahaman mengenai pengaruh kesadaran wajib pajak, pengetahuan perpajakan dan sanksi perpajakan di KPP Pratama Tabanan yang berpengaruh positif pada kepatuhan wajib pajak UMKM. Hasil penelitian ini dapat memberikan kontribusi positif dan menambah wawasan tentang faktor-faktor yang memengaruhi kepatuhan wajib pajak 
seperti kesadaran, pengetahuan dan sanksi perpajakan dan hendaknya menjadi bahan evaluasi bagi wajib pajak agar lebih meningkatkan kepatuhan dalam melaksanakan kewajiban perpajakannya. Berdasarkan hasil penelitian, disarankan agar lebih ditingkatkannya sosialisasi, transparansi, edukasi bagi wajib pajak oleh KPP Pratama Tabanan dan bagi peneliti selanjutnya dapat menambah variabel seperti umur, tingkat pendidikan, dan jenis kelamin yang mempengaruhi kepatuhan wajib pajak UMKM.

\section{REFERENSI}

Adnyana, I. G. A., \& Jati, I. K. (2018). Pengaruh Sanksi Perpajakan, Penggunaan E-Spt, Dan Kualitas Pelayanan Fiskus Pada Kepatuhan Wajib Pajak Orang Pribadi. E-Jurnal Akuntansi Universitas Udayana, 25, 2129-2154.

Afriyanti, N. N., \& Sari, M. M. R. (2012). Pengaruh Kepatuhan Wajib Pajak Dan Pemeriksaan Pajak Terhadap Penerimaan Pph Pasal 25/29 Wajib Pajak Badan Pada Kpp Pratama Denpasar Timur. Jurnal Ilmiah Akuntansi Dan Bisnis, 1-21.

Ajzen, I. (2005). Ajzeni-2005-attitudes-personality-and-behaviour-2nd-ed-openuniversity-press.pdf. International Journal of Strategic Innovative Marketing, 3, 117.

Andreas, \& Savitri, E. (2015). The Effect of Tax Socialization, Tax Knowledge, Expediency of Tax ID Number and Service Quality on Taxpayers Compliance with Taxpayers Awareness as Mediating Variables. Procedia Social and Behavioral Sciences, 211, 163-169. https://doi.org/10.1016/j.sbspro.2015.11.024

Ariyanto, D., Andayani, G. W., \& Putri, I. G. A. P. (2020). Influence of Justice, Culture and Love of Money Towards Ethical Perception on Tax Evasion with Gender as Moderating Variable. Journal of Money Laundering Control, 23(1), 245-266. https://doi.org/10.1108/JMLC-06-2019-0047

Brainyyah, M. Q., \& Rusydi, M. K. (2013). The Effect of Tax Fairness, Tax Knowledge, and Tax Complexity on Tax Compliance: The Case of SME Entrepreneurs' Taxpayers in Malang. Jurnal Ilmiah Mahasiswa FEB, 1, 1-17.

Budhiarsana, I. W., Dwirandra, A. A. N. ., \& Putra, I. N. W. A. (2016). Kepuasan Sebagai Pemoderasi Pengaruh Keadilan Distributif, Penegakan Sanksi pada Kepatuhan Wajib Pajak Hotel dan Restoran. E-Jurnal Ekonomi Dan Bisnis Universitas Udayana, 4, 721-748.

Budhiartama, I. G. P., \& Jati, I. K. (2016). Pengaruh Sikap, Kesadaran Wajib Pajak Dan Pengetahuan Perpajakan Pada Kepatuhan Membayar Pajak Bumi Dan Bangunan. E-Jurnal Akuntansi, 15(2), 1510-1535.

Cahyani, L. P. G., \& Noviari, N. (2019). Pengaruh Tarif Pajak, Pemahaman Perpajakan, dan Sanksi Perpajakan Terhadap Kepatuhan Wajib Pajak UMKM. E-Jurnal Akuntansi, 26(3), 1885-1911. https://doi.org/10.24843/eja.2019.v26.i03.p08

Devos, K., \& Zackrisson, M. (2015). Tax compliance and the public disclosure of tax information: An Australia/Norway comparison. EJournal of Tax Research, 13(1), 108-129.

Fischer, C. M., Wartick, M., \& Mark, M. M. (1992). Detection probability and taxpayer compliance: A review of the literature. Journal of Accounting 
Literature, 11, 1.

Fuadi, A. O., \& Mangoting, Y. (2013). Pengaruh Kualitas Pelayanan Petugas Pajak , Sanksi Perpajakan dan Biaya Kepatuhan Pajak Terhadap Kepatuhan Wajib Pajak UMKM. Tax \& Accounting Review, 1, 18-27.

Ghouri, A. M., Khan, N. R., \& Abdul Kareem, O. B. (2016). Improving Employees Behavior through Extension in Theory of Planned Behavior: A Theoretical Perspective for SMEs. International Journal of Business and Management, 11(11), 196. https://doi.org/10.5539/ijbm.v11n11p196

Handayani, O., \& Woro Damayanti, T. (2018). Determinants of Individual Taxpayers' Compliance in Indonesia: A Meta-Analysis. The Indonesian Journal of Accounting Research, 21(1), 1-22. https://doi.org/10.33312/ijar.332

Handke, L., \& Barthauer, L. (2019). Heider (1958): The Psychology of Interpersonal Relations (pp. 259-262). https://doi.org/10.1007/978-3-65821742-6_59

Hardiningsih, P., \& Yulianawati, N. (2011). Faktor-Faktor Yang Mempengaruhi Kemauan Membayar Pajak. Dinamika Keuangan Dan Perbankan, 3(1), 126-142. https://doi.org/ISSN: 1979-4878

Intrada, B., Wahyudi, T., \& Aswardi. (2019). The Influence of Personal Taxpayer Attitudes Related to the Implementation of Administrative Sanctions, Account Representative Services and Ability to Pay Tax Amnesty Ransom to the Compliance of Individual Taxpayers in Palembang City, Indonesia. Journal of Accounting Finance and Auditing Studies (JAFAS), 5(2), 38-56. https://doi.org/10.32602/jafas.2019.19

Karsimiati. (2009). Pengaruh Pelayanan Fiskus, Sanksi Denda dan Kesadaran Perpajakan Terhadap Kepatuhan Wajib Pajak dalam Membayar PBB di Kecamatan Gabus-Pati.

Katini, N. K. O. Y., \& Suardana, K. A. (2017). Pengaruh Kesadaran Wajib Pajak, Pengetahuan Perpajakan, Pelayanan Fiskus, Sanksi Administrasi Pada Kepatuhan Wajib Pajak Restoran. E-Jurnal Akuntansi Universitas Udayana, 19(1), 392-420.

Lewis, A. (1992). Tax evasion: An experimental approach. Journal of Economic Psychology, 13(1), 187-190. https://doi.org/10.1016/0167-4870(92)90059-g

Mangoting, Y., \& Sadjiarto, A. (2013). Pengaruh Postur Motivasi Terhadap Kepatuhan Wajib Pajak Orang Pribadi. Jurnal Akuntansi Dan Keuangan, 15(2). https://doi.org/10.9744/jak.15.2.106-116

Manual, V., \& Zhi Xin, A. (2016). Impact of Tax Knowledge, Tax Compliance Cost, Tax Deterrent Tax Measures towards Tax Compliance Behavior: A survey on Self-Employed Taxpayers in West Malaysia. Electronic Journal of Business and Management, 1(1), 56-70.

Markhumah, U. (2019). Pengaruh Ketegasan Sanksi Pajak, Pengetahuan Pajak, Tax Amnesty, Pelayanan Fiskus, Reformasi Perpajakan Terhadap Kepatuahan Wajib Pajak (Studi Empiris Pada Wajib Pajak Badan di KPP Pratama Surakarta). The 9th University Research Colliqium.

Muliari, N. K., \& Setiawan, P. E. (2010). Pengaruh persepsi tentang sanksi perpajakan dan kesadaran wajib pajak pada kepatuhan pelaporan wajib pajak orang pribadi di kantor pelayanan pajak pratama denpasar timur. EJurnal Akuntansi, 1-23. 
Nugroho, A., Andini, R., \& Raharjo, K. (2016). Pengaruh Kesadaran Wajib Pajak Dan Pengetahuan Perpajakan Wajib Pajak Terhadap Kepatuhan Wajib Pajak Dalam Membayar Pajak Penghasilan. Journal Of Accounting, 2(2), 1-13.

Nurkhin, A., Novanty, I., Muhsin, M., \& Sumiadji, S. (2018). The Influence of Tax Understanding, Tax Awareness and Tax Amnesty toward Taxpayer Compliance. Jurnal Keuangan Dan Perbankan, 22(2), 240-255.

Nurlis Islamiah Kamil. (2015). The Effect of Taxpayer Awareness , Knowledge , Tax Penalties and Tax Authorities Services on the Tax Complience : (Survey on the Individual Taxpayer at Jabodetabek \& Bandung ). Research Journal of Finance and Accounting, 6(2), 104-112.

Saad, N. (2013). Tax Knowledge, Tax Complexity and Tax Compliance: Taxpayers' View. Procedia - Social and Behavioral Sciences, 109(1), 1069-1075. https://doi.org/10.1016/j.sbspro.2013.12.590

Sari, A. P., \& Wirakusuma, M. G. (2018). Persepsi Tax Amnesty Sebagai Pemoderasi Pengaruh Kesadaran Wajib Pajak dan Sanksi Perpajakan Pada Kepatuhan WPOP. E-Jurnal Akuntansi, 22, 464-491. https://doi.org/10.24843/EJA.2018.v22.i01.p18

Sentanu, I. N. W., \& Setiawan, P. E. (2016). Pengaruh Kualitas Pelayanan, Kewajiban Moral dan Sanksi Perpajakan Pada Kepatuhan Pajak Hotel. EJurnal Akuntansi, 16, 306-332.

Setiawan, E. Y. (2015). Pengaruh kesadaran wajib pajak, pelayanan fiskus, dan sanksi perpajakan terhadap kepatuhan wajib pajak umkm dalam pelaporan kewajiban perpajakan (Studi kasus pada Wajib Pajak UMKM yang terdaftar di KPP Pratama Blitar). Universitas Islam Negeri Maulana Malik Ibrahim, 149.

Sulistiyani, R., \& Harwiki, W. (2016). How SMEs Build Innovation Capability Based on Knowledge Sharing Behavior? Phenomenological Approach. Procedia - Social and Behavioral Sciences, 2(9), 741-747. https://doi.org/10.1016/j.sbspro.2016.05.070

Suriambawa, A., \& Setiawan, P. E. (2018). Sosialisasi Perpajakan Memoderasi Pengaruh Kesadaran Wajib Pajak dan Sanksi Perpajakan Pada Kepatuhan WPOP. E-Jurnal Akuntansi, 2185. https://doi.org/10.24843/eja.2018.v25.i03.p21

Susilawati, K. E., \& Budiartha, K. (2013). Pengaruh kesadaran wajib pajak, pengetahuan pajak, sanksi perpajakan dan akuntabilitas pelayanan publik pada kepatuhan wajib pajak kendaraan bermotor. E-Jurnal Akuntansi Universitas Udayana, 2, 345-357. https://doi.org/ISSN: 2302-8556 